\title{
Synthesis, Structural Characterization, and Thermal Properties of the Poly(methylmethacrylate) $/ \delta$-FeOOH Hybrid Material: An Experimental and Theoretical Study
}

\author{
Silviana Corrêa, ${ }^{1}$ Lívia C. T. Lacerda, ${ }^{1}$ Maíra dos S. Pires, ${ }^{1}$ Marcus V. J. Rocha, ${ }^{1,2}$ \\ Francisco G. E. Nogueira, ${ }^{3}$ Adilson C. da Silva, ${ }^{4}$ Marcio C. Pereira, ${ }^{5}$ Angela D. B. de Brito, ${ }^{6}$ \\ Elaine F. F. da Cunha, ${ }^{1}$ and Teodorico C. Ramalho ${ }^{1,7}$ \\ ${ }^{1}$ Department of Chemistry, Federal University of Lavras, No. 37, 37200000 Lavras, MG, Brazil \\ ${ }^{2}$ Department of Theoretical Chemistry, Vrije Universiteit Amsterdam, De Boelelaan 1083, 1081 HV Amsterdam, Netherlands \\ ${ }^{3}$ Institute of Chemistry of São Carlos, University of São Paulo, Avenue Trabalhador São Carlense, 400, 13560970 São Carlos, SP, Brazil \\ ${ }^{4}$ Institute of Exact Sciences and Biological, Department of Chemistry, Federal University of Ouro Preto, Room 25, ICEB 3 Bauxita, \\ 35400000 Ouro Preto, MG, Brazil \\ ${ }^{5}$ Institute of Science, Engineering and Technology, Federal University of the Jequitinhonha and Mucuri Valleys, \\ 39803-371 Teófilo Otoni, MG, Brazil \\ ${ }^{6}$ Department of Physics, Federal University of Lavras, No. 37, 37200000 Lavras, MG, Brazil \\ ${ }^{7}$ Center for Basic and Applied Research, Faculty of Informatics and Management, University of Hradec Kralove, \\ 50000 Hradec Kralove, Czech Republic
}

Correspondence should be addressed to Teodorico C. Ramalho; teo@dqi.ufla.br

Received 31 August 2015; Revised 2 November 2015; Accepted 10 November 2015

Academic Editor: Alessandro Pegoretti

Copyright (C) 2016 Silviana Corrêa et al. This is an open access article distributed under the Creative Commons Attribution License, which permits unrestricted use, distribution, and reproduction in any medium, provided the original work is properly cited.

The $\delta$-FeOOH/PMMA nanocomposites with 0.5 and $2.5 \mathrm{wt}$.\% of $\delta$-FeOOH were prepared by grafting 3-(trimethoxysilyl)propyl methacrylate on the surface of the iron oxyhydroxide particles. The FTIR spectra of the $\delta$-FeOOH/PMMA nanocomposites showed that the silane monomers were covalently attached to the $\delta$-FeOOH particles. Because of the strong interaction between the PMMA and $\delta$-FeOOH nanoparticles, the thermal stability of the $\delta$-FeOOH/PMMA nanocomposites was improved compared to the pure PMMA. The SEM analysis conferred the size agglomerate of particles regarding the morphology of samples. The theoretical study enabled a better understanding of the interaction of the polymer with the iron oxyhydroxide. The DFT-based calculations reinforce the radical trapping mechanism of stabilization of nanocomposites; that is, $\mathrm{Fe}^{3+}$ species might be able to accept electrons coming from the organic phase that decomposes via radical unzipping. The radical scavenge effect delays the weight loss of polymer.

\section{Introduction}

Nanocomposites are part of broad family of materials called organic-inorganic hybrid materials. The organic phase is comprised of polymers and the inorganic phase can be constituted of a wide variety of materials, such as metal nanoparticles, oxide nanoparticles, nanotubes, or clays [1,2].

In nanocomposites, as in other organic-inorganic hybrids, the phases are dispersed at the molecular or nanometric level, while, in microcomposites or conventional composites, inorganic fillers are dispersed at a micrometric scale. This means that, in conventional composites, the phases are immiscible [3].

The use of the magnetic materials to synthesis organicinorganic hybrids with polymer matrix has been developed to explore the physical and chemical properties. The polymers can be modeled to afford a particular architecture and arrangement of the particles, which could allow the incorporation of inorganics particles [4].

Materials that can appropriately replace living tissues are called biomaterials and must present physical and biological properties consistent with these host tissues, to stimulate an 
adequate response. Such property characterizes biocompatibility [5].

The uses of these materials in controlled release drug to bone regeneration procedures are reported in studies. In keeping with Soundrapandian and collaborators [6], polymers and ceramics are applied in nanomaterials for drug delivery in the bones. The carrier materials selected for drug delivery in bones are expected to be affordable and need exhibit predictable release characteristics, biologically and mechanically compatible with local bone tissue.

The influence of the magnetic field on the controlled release of fluorescein isothiocyanate using nanoparticles of magnetite/PMMA - poly(methylmethacrylate) - and cobalt/ PMMA has been studied by Urbina and collaborators [7]. The results showed a higher rate of release material with the magnetite.

In this context, hybrids based on PMMA and iron oxides have been studied in recent years, especially with magnetic iron oxides. However, the magnetic property would only be guaranteed in modified polymers if there was a maximum dispersion of iron oxide on the polymeric matrix. Subsequently, PMMA was considered a suitable dispersant of magnetite nanoparticles [8].

Among the magnetic iron oxides, $\delta$-FeOOH has attracted special attention due to its stability in biochemical media [9]. $\delta$-FeOOH is a polymorph of several common iron oxyhydroxides with a structure that is based on a hexagonal close-packed oxygen lattice similar to that of hematite $(\alpha$ $\mathrm{Fe}_{2} \mathrm{O}_{3}$ ) with iron occupying half of the available octahedral interstices [9]. Due to its superparamagnetic properties [10], $\delta$-FeOOH is a potentially interesting material to be used in modern medicine. Despite its great importance, surprisingly little detailed computational and experimental work on this subject has appeared.

Thus, the current work aims to develop $\delta$-FeOOH/ PMMA hybrids, characterizing their structure, morphology, and thermal properties by using several experimental techniques as well as to perform theoretical investigations involving structural and electronic parameters.

\section{Materials and Methods}

2.1. Synthesis of PMMA/ $\delta$-FeOOH Films. The synthesis of $\delta$ $\mathrm{FeOOH}$ was carried out according to the modified procedure described by Chagas and collaborators [10]. It consists of precipitating $\mathrm{Fe}^{2+}$ alcoholic solution with $\mathrm{NaOH}$ followed by fast oxidation with $\mathrm{H}_{2} \mathrm{O}_{2}$, enabling the direct attainment of the $\delta$-FeOOH.

The 3-(trimethoxysilyl)propyl methacrylate (Aldrich) (TMSM) was used to graft the nanoparticles. For that $500 \mathrm{mg}$ of dried nanoparticles was dispersed in a solution of $1 \mathrm{~mL}$ of TMSM and $2 \mathrm{~mL}$ of tetrahydrofuran (THF, Aldrich). This mixture was kept in an ultrasound bath for 24 hours at $55^{\circ} \mathrm{C}$. The nanoparticles were washed three times with toluene (Aldrich) and recuperated by centrifugation $(7000 \mathrm{~g}$ for $30 \mathrm{~min}$ ); then they were dried for 24 hours at $50^{\circ} \mathrm{C}$.

Finally, the grafted nanoparticles were dispersed by ultrasound during 4 hours in $2 \mathrm{~mL}$ of THF and mixed with
$2.015 \mathrm{~mL}$ of methylmethacrylate (Aldrich) (MMA), $2 \mathrm{~mL}$ of THF, and $5 \mathrm{mg}$ of BPO (Benzoyl Peroxide). This mixture was then kept under ultrasound for 2 hours. Polymerization of MMA was made by keeping the samples for 12 hours at $70^{\circ} \mathrm{C}$. The nanocomposites were deposited on Teflon ${ }^{\mathrm{Tm}}$ sheets and then dried under air atmosphere for 24 hours at room temperature. The resulting free (not supported) films were dried for 12 hours at $100^{\circ} \mathrm{C}$.

2.2. Characterization. The nanostructures of the hybrid films were characterized by Fourier transform infrared (FTIR) spectroscopy using Spectrum 2000 PerkinElmer. FTIR measurements were performed in attenuated total reflexion (ATR) mode, thus obtaining vibrational absorption spectra over a spectral range of $4000-400 \mathrm{~cm}^{-1}$.

The crystalline structure was analyzed by X-ray powder diffraction (XRD). Data were obtained using X'Pert Pro multipurpose $\mathrm{X}$-ray diffraction (MPD) system employing $\mathrm{Cu}$ $\mathrm{K} \alpha$ radiation $(\lambda=0.154 \mathrm{~nm})$ operated at $40 \mathrm{~mA}$ and $45 \mathrm{kV}$.

Scanning electron microscopy (SEM) was performed on samples using LEO VP 435 scanning electron microscope operating at $20 \mathrm{kV}$.

The thermogravimetric analyses were performed in triplicate using a Mettler Toledo equipment (TG/DSC1) Star System, using $10 \mathrm{mg}$ of sample, in the temperatures of 25 to $1000^{\circ} \mathrm{C}$ with a heating rate of $10^{\circ} \mathrm{C} \mathrm{min}^{-1}$ in a synthetic air atmosphere.

2.3. Computational Details. All calculations were performed with DFT (Density Functional Theory) method using the ADF-BAND 2009.01 program [11, 12]. The performance for computing the geometries has been done by the PBE density functional. In conjunction with PBE density functional, the TZP basis set has been used, which is a large uncontracted set of Slater-type orbitals containing diffuse functions, which is of triple- $\zeta$ quality and has been improved with one set of polarization function: $3 \mathrm{~d}$ on carbon and silicon, $4 \mathrm{f}$ on iron, and $2 \mathrm{p}$ on hydrogen. The frozen core approximation was used in the inner cores of $\mathrm{O}(1 \mathrm{~s})$ and $\mathrm{Fe}(1 \mathrm{~s} 2 \mathrm{~s} 2 \mathrm{p})$ atoms.

The $\delta$-FeOOH structure was built using the parameters based on previous studies [13], with space group P-3m1. It has only $\mathrm{Fe}^{3+}$ atoms at the octahedral sites " 0,0 , and 0 " and " 0,0 , and $1 / 2$." The positions of $\mathrm{O}$ and $\mathrm{H}$ atoms are defined by their coordinates " $1 / 3,2 / 3$, and 0.2468 " and " $1 / 3,2 / 3$, and 0.51," the lattices parameters $a=2.946 \AA$ and $c=4.552 \AA$ For the potential surface energy calculation, were varied the PMMA angles of 80 to $200^{\circ}$ about the iron oxyhydroxide.

\section{Results and Discussion}

3.1. Structural Characterization. In the present work $\delta$ $\mathrm{FeOOH}$ and the grafted $\delta$-FeOOH/TMSM samples were characterized with ATR infrared spectroscopy. The obtained results are summarized in Figure 1. The ATR spectrum of $\delta$ $\mathrm{FeOOH}$ (Figure 1) shows a very strong and broad band at $3265 \mathrm{~cm}^{-1}$ that can be associated with the stretching modes of molecules water, present on its surface. The two bands at $1096 \mathrm{~cm}^{-1}$ and $908 \mathrm{~cm}^{-1}$ correspond to $\mathrm{Fe}-\mathrm{O}-\mathrm{H}$ bending 


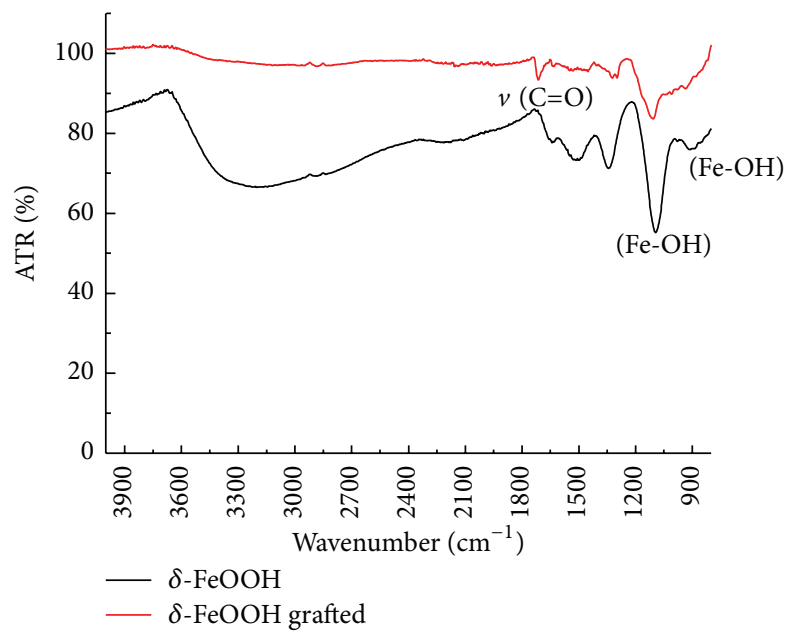

FIgURE 1: FTIR spectra of $\delta$-FeOOH and grafted $\delta$-FeOOH.

vibrations [13]. The most remarkable band is located at $1701 \mathrm{~cm}^{-1}$ and it corresponds to carbonyl $(\mathrm{C}=\mathrm{O})$ vibrations on TMSM structure. The infrared spectrum of functionalized $\delta$-FeOOH showed a band centered at $1096 \mathrm{~cm}^{-1}$, which can be attributed to $\mathrm{Si}-\mathrm{O}-\mathrm{Fe}$ vibrations $[14,15]$. It suggests that the silane monomers were covalently bonded to $\delta$-FeOOH particles. It should be kept in mind, however, that the infrared bands are attributed to $\mathrm{Fe}-\mathrm{O}-\mathrm{H}$ bending vibrations in the same region. Despite this feature, the functionalization occurs in the formation of the $\mathrm{Si}-\mathrm{O}-\mathrm{Fe}$ bonding, because the $\mathrm{Fe}-\mathrm{O}-\mathrm{H}$ bending vibration at $908 \mathrm{~cm}^{-1}$ disappears in $\delta$ $\mathrm{FeOOH} / \mathrm{TMSM}$ infrared spectrum. Probably, one or two Si$\mathrm{OCH}_{3}$ groups are broken after functionalization reaction. Figure 2 represents the atomic model of $\delta$-FeOOH/PMMA hybrid material.

The loss of two or three methyl groups of TMSM led to a new chemical bond between oxygen atoms from $\delta$ $\mathrm{FeOOH}$ and silicon. The nucleophilic substitution of $\mathrm{Fe}-\mathrm{OH}$ into $\mathrm{Si}\left(\mathrm{OCH}_{3}\right)$ can be described as

$$
\mathrm{Fe}-\mathrm{OH}+\mathrm{Si}-\mathrm{OCH}_{3} \longrightarrow \mathrm{Fe}-\mathrm{O}-\mathrm{Si}+\mathrm{CH}_{3} \mathrm{OH}
$$

In the study of Pereira and collaborators [9], there were found peaks in the X-ray diffraction pattern "100," "101," "102," and "110" characteristic of $\delta$-FeOOH. The lattice parameters can be indexed on a hexagonal lattice with $a=$ $2.946 \AA$ and $c=4.552 \AA$.

The XRD patterns were recorded for the nanoparticles after grafting with TMSM molecules. Figures 3(a) and 3(b) reveal the presence of peaks $2 \theta=36^{\circ}, 56^{\circ}$, and $63^{\circ}$, approximately, corresponding to the "100," "102," and "110," to the grafted $\delta$-FeOOH 0.5 wt. $\%$ and 2.5 wt. $\%$.

The XRD showed bands characteristic of PMMA such as in the study of Shobhana and the peaks of $\delta$-FeOOH [16] confirming the presence of PMMA and $\delta$-FeOOH in this material. Because the main peaks are represented in both XRD patterns, in the second (Figure $3(\mathrm{~b})$ ), the peak intensity is smaller; it can be interpreted by the fact that sample has a higher percentage of feroxyhyte $2.5 \mathrm{wt} . \%$. Already in Figure 3(a), the intensity is large for the grafted $\delta$-FeOOH 0.5 wt.\%.

Figures 4(a) and 4(b) show the images obtained by SEM of surface and cross section fractured under liquid nitrogen of hybrids with $2.5 \mathrm{wt}$. $\%$ of $\delta$-FeOOH nanoparticles, respectively.

A general analysis of the micrographs of all samples shows agglomerates of different sizes and with irregular blocks formats throughout the film. The average size of the agglomerates was larger than $1 \mu \mathrm{m}$ to $30 \mu \mathrm{m}$, indicating a broad size distribution.

3.2. Thermal Properties. The thermal stabilities of the obtained hybrid materials were determined by thermogravimetric analysis (TGA) and differential thermogravimetric (DTA).

Figures 5 and 6 display the TG and DTA curves of PMMA, $\delta$-FeOOH grafted with TMSM, and $\delta$-FeOOH/PMMA hybrid. These TG and DTA curves indicate that the neat $\delta$ FeOOH and $\delta$-FeOOH/TMSM sample weight loss occurs in two and three distinct steps, respectively. For both of the materials, the first step of weight loss can be attributed to the free water in the powder. For neat $\delta$-FeOOH particles, about $11 \%$ weight loss is observed at $273^{\circ} \mathrm{C}$, which is due to the crystal transition of $\delta$-FeOOH to hematite [13].

By analyzing the $\delta$-FeOOH grafted with TMSM, after the first step attributed to the free water in the powder, it can be related to another weight loss at $289^{\circ} \mathrm{C}$, which is due to the silane groups grafted on the iron oxyhydroxide surface. The grafting process shifted the second decomposition step of $\delta$ $\mathrm{FeOOH}$ at $340^{\circ} \mathrm{C}$ to higher values, suggesting higher thermal stability.

Concerning the thermal decomposition of PMMA, this can take place in three stages: the first step between 130 and $260^{\circ} \mathrm{C}$ is related to the decomposition starting at the headto-head chain segments. The second step between 260 and $370^{\circ} \mathrm{C}$ is attributed to first unzipping starting at unsaturated polymer end chains, and the third step between 370 and $500^{\circ} \mathrm{C}$ corresponds to the random joining of polymeric chains $[17,18]$.

The DTA curves shown in Figure 6 indicate that the starting temperature of the second decomposition step is shifted to higher values for increasing $\delta$-FeOOH loading, while the end of this step is only slightly affected by $\delta$ FeOOH content. This implies that the increasing amount of $\delta$-FeOOH nanoparticles delays the beginning of polymer unzipping. However, during the decomposition the $\delta$ $\mathrm{FeOOH}$ nanoparticles confer suppressing effect that seems to be independent of their loading in the nanocomposite, at least within the 0.5 to $2.5 \mathrm{wt} . \%$ range presented in this study.

We can also notice, in Figure 6, that the maximum degradation rate of PMMA occurs at $293^{\circ} \mathrm{C}$, while increasing $\delta$-FeOOH loading this maximum shifts toward higher temperatures, from $T=378^{\circ} \mathrm{C}$ for $\delta$-FeOOH 0.5 wt. $\%$ up to $389^{\circ} \mathrm{C}$ for $\delta$-FeOOH 2.5 wt. $\%$. 


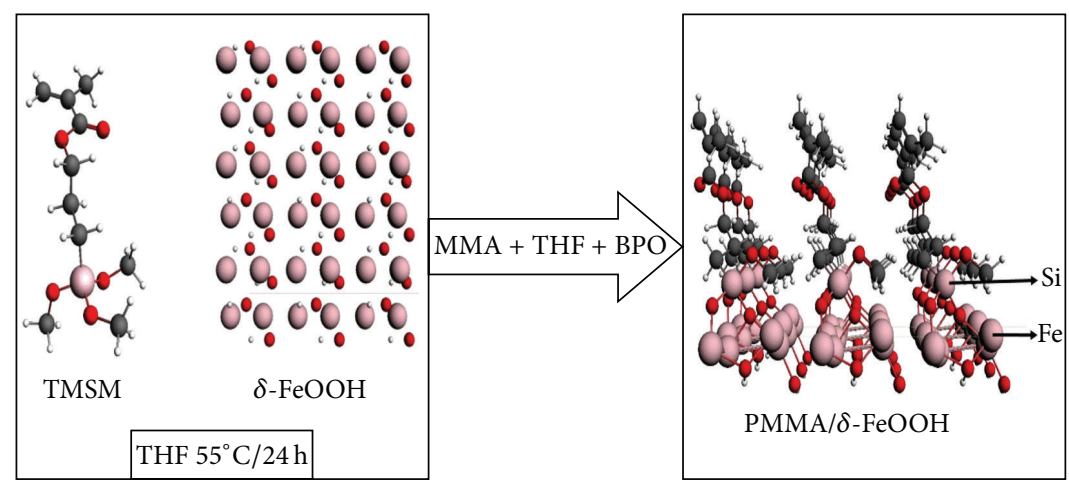

FIgUre 2: Atomic model of a $\delta$-FeOOH nanocrystal embedded in the PMMA.

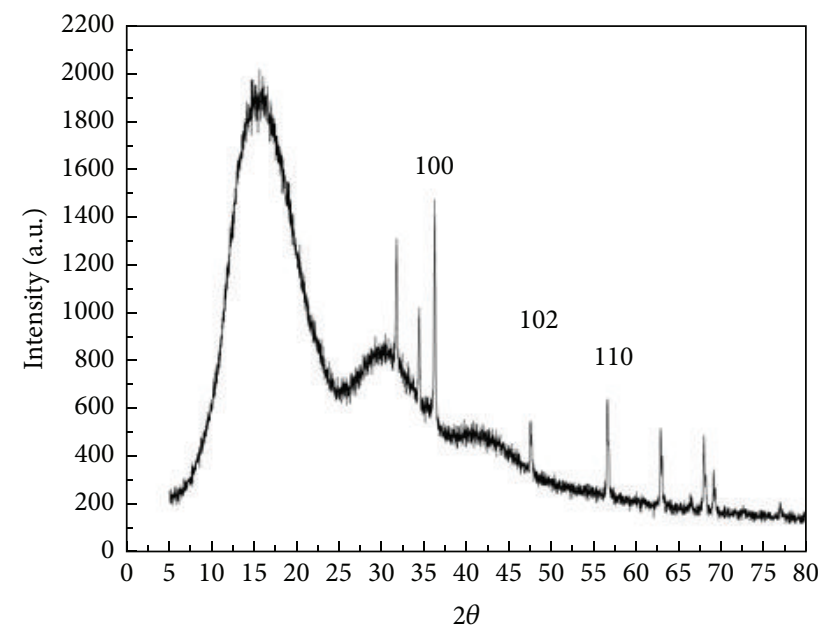

(a) Polymer 0.5 wt.\% FeOOH

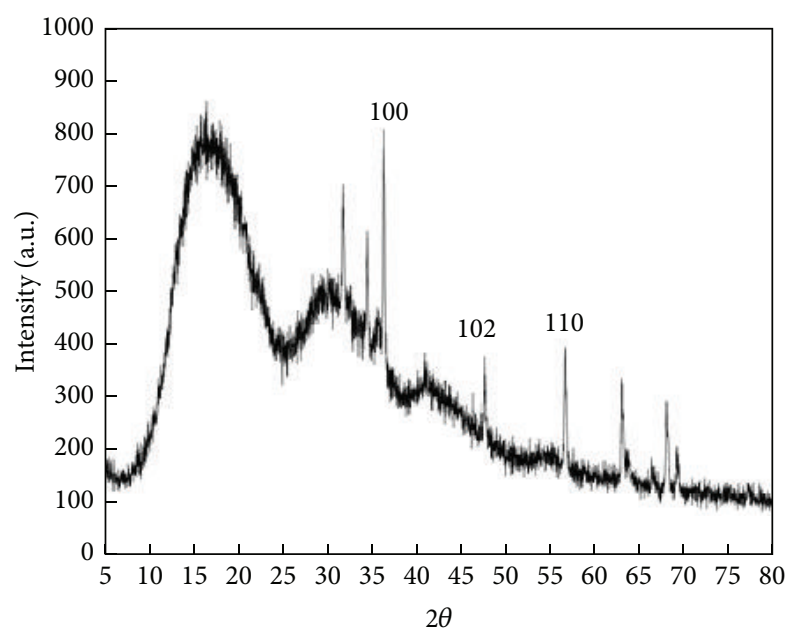

(b) Polymer 2.5 wt. $\% \mathrm{FeOOH}$

Figure 3: Powder X-ray diffraction pattern of grafted $\delta$-FeOOH 0.5 wt.\% (a) and 2.5 wt.\% (b) sample.

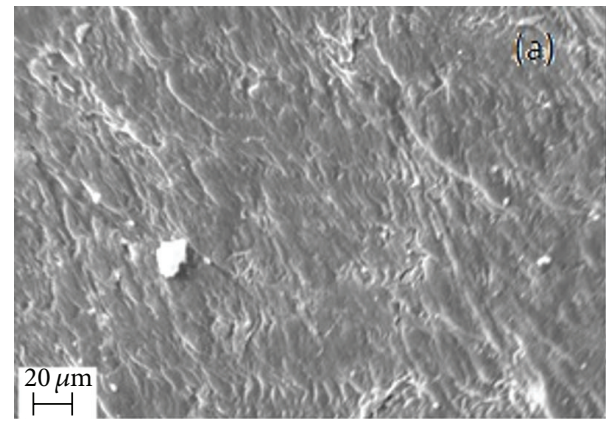

(a)

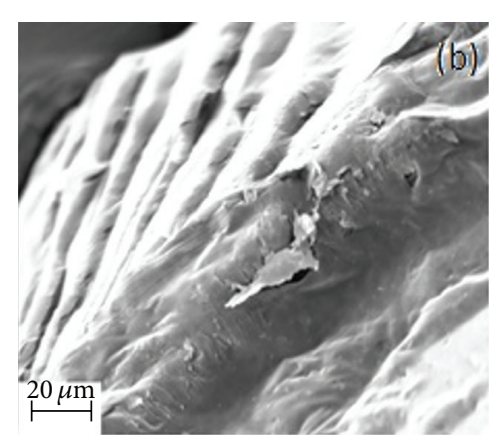

(b)

FIgURE 4: SEM micrographs of PMMA/ $\delta$-FeOOH hybrid with (a) 0.5 and (b) 2.5 wt. $\%$ of $\delta$-FeOOH.

The radical trapping effect might be the responsible for the thermal stability improvement observed for the increasing amount of $\delta$-FeOOH nanoparticles. This effect was recently demonstrated for inorganic hybrids with PMMA [19-22]. Therefore the thermal improvement reported above may take place due to a similar effect that may be undergoing in the presence of $\delta$ - $\mathrm{FeOOH}$, which acts as radical trappers and accepts the unpaired electron from the radical polymer chain thus stopping or retarding the unzipping.

3.2.1. $\delta$ - $\mathrm{FeOOH}$ Bulk. For study, theoretical calculations with the relativistic effects DFT/ZORA/PBE method of the surface 


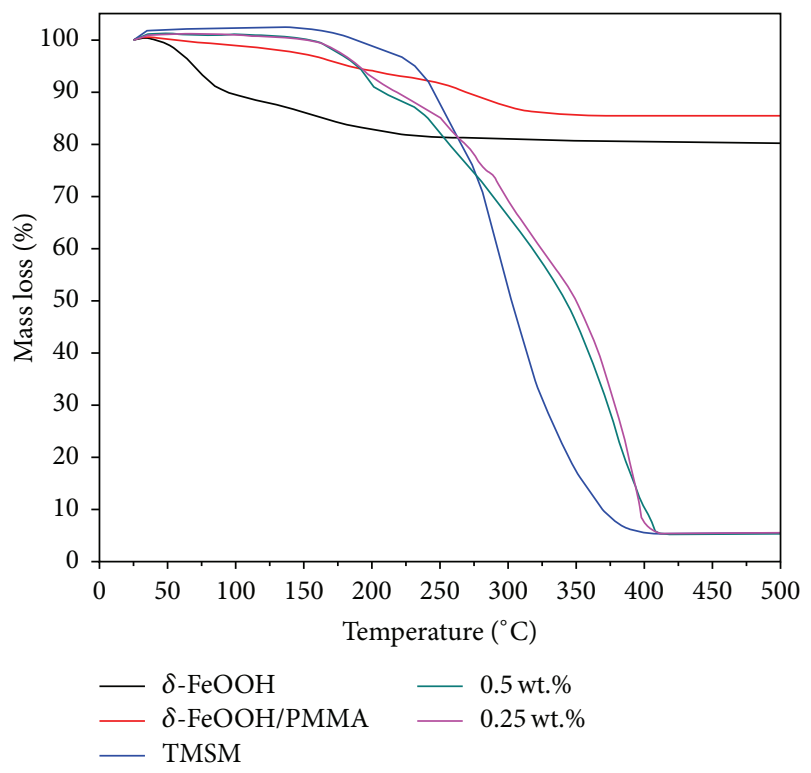

FIgURE 5: Thermogravimetric curves of pure PMMA and PMMA with different $\delta$ - $\mathrm{FeOOH}$ contents.

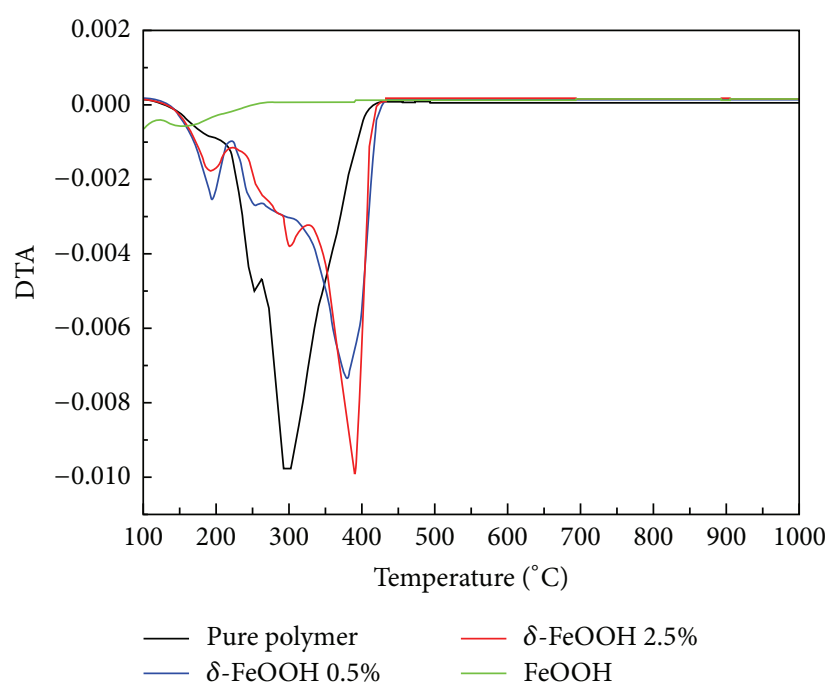

FIgURE 6: Differential thermogravimetric (DTA) curves of $\delta$ $\mathrm{FeOOH}$, Polymer, and $\delta$-FeOOH/PMMA hybrid 0.5 and 2.5 wt.\%.

of $\delta$ - $\mathrm{FeOOH}$ before the functionalization process were performed. From the planes examined, "100," "101," "102," and "110," the more stable one was "100."

In the density of states (DOS) graphs, the valence band located in the region of the oxygen $2 \mathrm{p}$ and the conduction band situated in the region of the iron $3 \mathrm{~d}$ (Figure 7) indicate an electron transfer from $\mathrm{O}^{2-}$ anions to $\mathrm{Fe}^{3+}$ cations.

Figure 8 shows areas with high and low electron density in green and red color, respectively. The valence charge density is higher in the volumes close to $\mathrm{O}$ atoms. These are preferential regions for nucleophilic or electrophilic substitution, where $\mathrm{Fe}-\mathrm{OH}$ reacts with $\mathrm{Si}-\mathrm{OCH}_{3}$ to originate $\mathrm{Fe}-\mathrm{O}-\mathrm{Si}$ bonds.
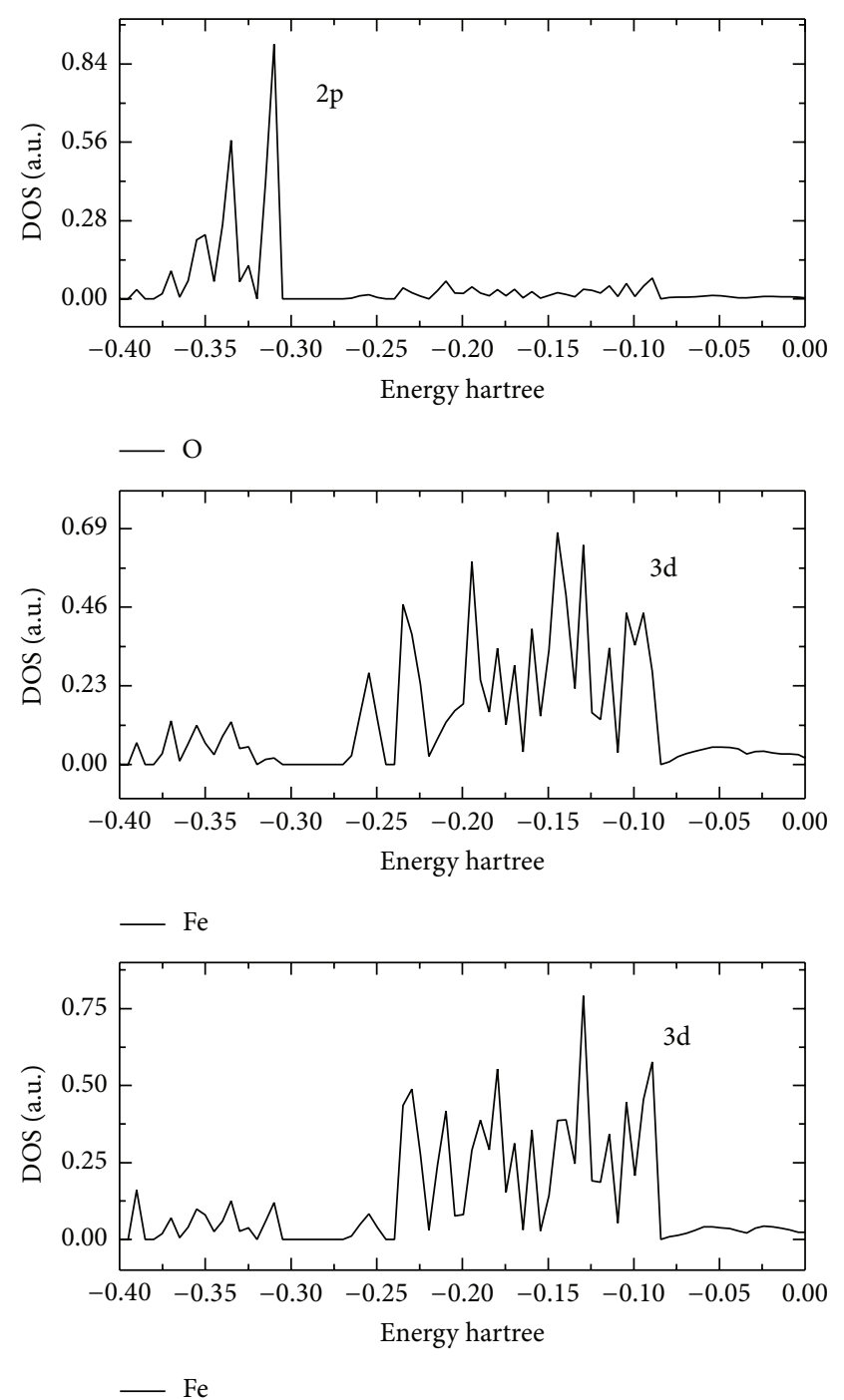

FIgure 7: Densities of states (DOS) of octahedral Fe and $\mathrm{O}$ in the bulk $\delta$-FeOOH.

3.2.2. $P M M A / \delta-F e O O H$. The potential energy surface varying the PMMA angle in relation to the oxide surface by angles (I) Si-C-C-C and (II) C-C-O-C from 80 to $200^{\circ}$ has been determined. This feature allowed us to evaluate the probable conformation of the monomer of the polymeric matrix close to the surface of feroxyhyte nanoparticles. Our results plotted in Figure 9 indicate that the minimum energy or most stable conformation of PMMA molecule on the $\delta$ - $\mathrm{FeOOH}$ surface lies in the range of $155-130^{\circ}$.

The $\delta$ - $\mathrm{FeOOH}$ surface interferes in the PMMA angles so that the system stability increases while angles I and II reduce. This phenomenon can be explained by attractive electrostatic interactions, either between the positive regions of the PMMA and the surface oxygen or between $\pi$-electrons of the end of the molecule and the empty orbital of iron atoms present on the surface. This trend prevailed while the electronic effects were greater than the steric effects. 


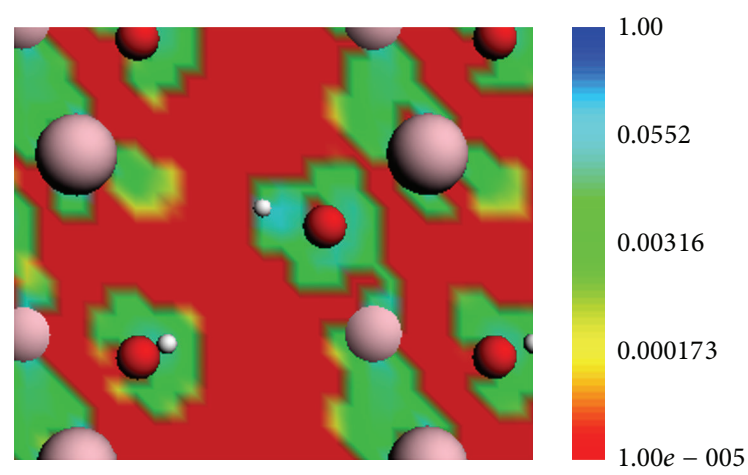

FIGURE 8: Electrostatic surface contours of $\delta$-FeOOH bulk. Red and green indicate volumes of low electron density and high electron density, respectively. Red $=$ oxygen, white $=$ hydrogen, and pink = iron.

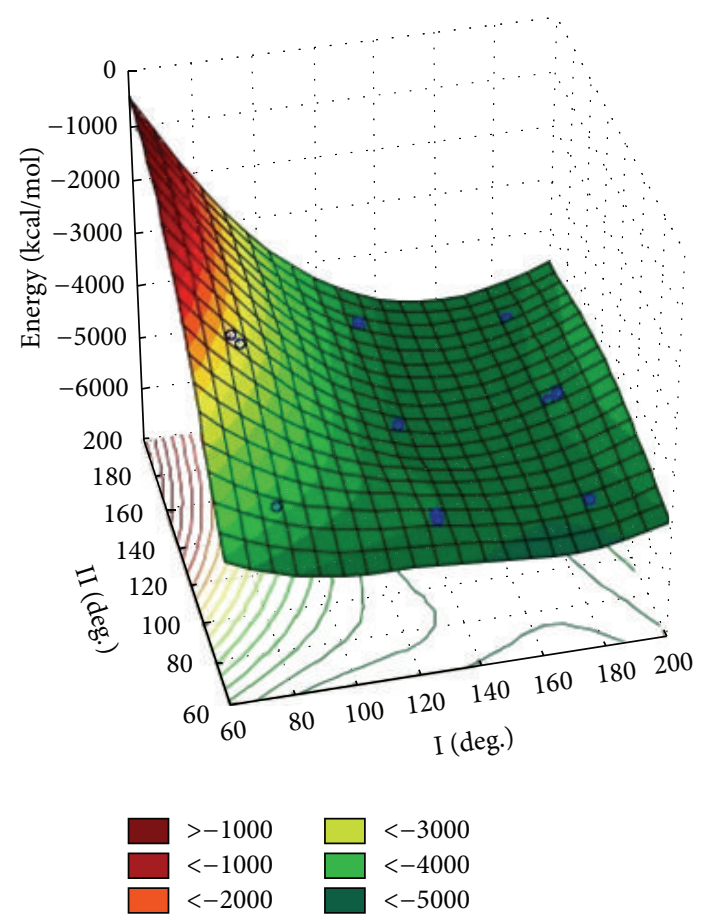

FIGURE 9: Surface potential energy of $\delta$-FeOOH/PMMA as a function of the (I) Si-C-C-C and (II) C-O-C-C angles. 3D surface: $1^{\prime}$ versus $2^{\prime}$ versus energy. Energy = distance weighted least squares.

\section{Conclusions}

The hybrid nanocomposites $\delta$-FeOOH/PMMA were successfully prepared. The results of SEM confirmed the dispersion of $\delta$-FeOOH particles in the polymer matrix.

The TG analysis showed that the thermal stability of $\delta$ $\mathrm{FeOOH} / \mathrm{PMMA}$ nanocomposites is higher than that of pure PMMA. This trend became more evident by increasing the iron concentration.

The results of FTIR indicate the existence of covalent bonding between silane monomers and atoms located on the surface of the $\delta$-FeOOH nanoparticles. This was confirmed by surface charge density map, which clearly showed the presence of regions likely to perform this type of interaction.

In general, the computational studies, coupled with experimental characterizations, allowed a better understanding of the morphology, structure, and electronic properties of hybrid $\delta$-FeOOH/PMMA.

\section{Conflict of Interests}

All authors declare that there is no conflict of interests regarding the publication of this paper.

\section{Acknowledgments}

The authors thank the Brazilian agencies FAPEMIG, CAPES, and $\mathrm{CNPq}$ for funding this work. They are also especially grateful to CNPq and CAPES for the fellowships and scholarships provided. Teodorico C. Ramalho thanks also the Invited Professor position at the Center for Basic and Applied Research at the Czech Republic.

\section{References}

[1] P. Kiliaris and C. D. Papaspyrides, "Polymer/layered silicate (clay) nanocomposites: an overview of flame retardancy," Progress in Polymer Science, vol. 35, no. 7, pp. 902-958, 2010.

[2] F. Hussain, M. Hojjati, M. Okamoto, and R. E. Gorga, "Review article: polymer-matrix nanocomposites, processing, manufacturing, and application: an overview," Journal of Composite Materials, vol. 40, no. 17, pp. 1511-1575, 2006.

[3] J. Macan, I. Brnardić, S. Orlić, H. Ivanković, and M. Ivanković, "Thermal degradation of epoxy-silica organic-inorganic hybrid materials," Polymer Degradation and Stability, vol. 91, no. 1, pp. 122-127, 2006.

[4] S. Gross, D. Camozzo, V. Di Noto, L. Armelao, and E. Tondello, "PMMA: a key macromolecular component for dielectric lowK hybrid inorganic-organic polymer films," European Polymer Journal, vol. 43, no. 3, pp. 673-696, 2007.

[5] G. Toskas, C. Cherif, R. Hund et al., "Chitosan(PEO)/silica hybrid nanofibers as a potential biomaterial for bone regeneration," Carbohydrate Polymers, vol. 94, no. 2, pp. 713-722, 2013.

[6] C. Soundrapandian, B. Sa, and S. Datta, "Organic-inorganic composites for bone drug delivery," AAPS PharmSciTech, vol. 10, no. 4, pp. 1158-1171, 2009.

[7] M. C. Urbina, S. Zinoveva, T. Miller, C. M. Sabliov, W. T. Monroe, and C. S. S. R. Kumar, "Investigation of magnetic nanoparticle-polymer composites for multiple-controlled drug delivery," Journal of Physical Chemistry C, vol. 112, no. 30, pp. 11102-11108, 2008.

[8] S. Kirchberg, M. Rudolph, G. Ziegmann, and U. A. Peuker, "Nanocomposites based on technical polymers and sterically functionalized soft magnetic magnetite nanoparticles: synthesis, processing, and characterization," Journal of Nanomaterials, vol. 2012, Article ID 670531, 8 pages, 2012.

[9] M. C. Pereira, E. M. Garcia, A. Cândido Da Silva et al., "Nanostructured $\delta$-FeOOH: a novel photocatalyst for water splitting," Journal of Materials Chemistry, vol. 21, no. 28, pp. 10280-10282, 2011.

[10] P. Chagas, A. C. Da Silva, E. C. Passamani et al., " $\delta$-FeOOH: a superparamagnetic material for controlled heat release under 
AC magnetic field," Journal of Nanoparticle Research, vol. 15, no. 4, article 1544, 2013.

[11] G. Te Velde, F. M. Bickelhaupt, E. J. Baerends et al., "Chemistry with ADF," Journal of Computational Chemistry, vol. 22, no. 9, pp. 931-967, 2001.

[12] BAND 2009.01, SCM, Theoretical Chemistry, Vrije Universiteit, Amsterdam, The Netherlands, 2009, http://www.scm.com/.

[13] R. M. Cornell and U. Schwertmann, The Iron Oxides, WileyVCH, Weinheim, Germany, 2nd edition, 2003.

[14] U. Schwertmann and H. Thalmann, "The influence of [Fe(II)], [Si], and $\mathrm{pH}$ on the formation of lepidocrocite and ferrihydrite during oxidation of aqueous $\mathrm{FeCl}_{2}$ solutions," Clay Minerals, vol. 11, no. 3, pp. 189-200, 1976.

[15] L. Carlson and U. Schwertmann, "Natural occurrence of feroxyhite $\left(\delta^{\prime}-\mathrm{FeOOH}\right), "$ Clay and Clays Minerals, vol. 28, no. 4, pp. 272-280, 1980.

[16] E. Shobhana, "X-Ray diffraction and UV-visible studies of PMMA thin films," International Journal of Modern Engineering Research, vol. 2, no. 3, pp. 1092-1095, 2012.

[17] P. R. Westmoreland, T. Inguilizian, and K. Rotem, "Flammability kinetics from TGA/DSC/GCMS, microcalorimetry and computational quantum chemistry," Thermochimica Acta, vol. 367-368, pp. 401-405, 2001.

[18] T. Kashiwagi, A. Inaba, J. E. Brown, K. Hatada, T. Kitayama, and E. Masuda, "Effects of weak linkages on the thermal and oxidative degradation of poly(methyl methacrylates)," Macromolecules, vol. 19, no. 8, pp. 2160-2168, 1986.

[19] P. K. Sahoo and R. Samal, "Fire retardancy and biodegradability of poly(methyl methacrylate)/montmorillonite nanocomposite," Polymer Degradation and Stability, vol. 92, no. 9, pp. 17001707, 2007.

[20] M. A. Goncalves, E. F. F. da Cunha, F. C. Peixoto, and T. C. Ramalho, "Probing thermal and solvent effects on hyperfine interactions and spin relaxation rate of $\delta-\mathrm{FeOOH}\left(\begin{array}{lll}1 & 0 & 0\end{array}\right)$ and $\left[\mathrm{MnH}_{3} \text { buea }(\mathrm{OH})\right]^{2-}$ : toward new MRI probes," Computational and Theoretical Chemistry, vol. 1069, pp. 96-104, 2015.

[21] M. A. Goncalves, E. F. F. da Cunha, F. C. Peixoto, and T. C. Ramalho, "NMR parameters and hyperfine coupling constants

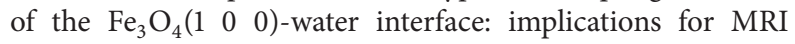
probes," Chemical Physics Letters, vol. 609, pp. 88-92, 2014.

[22] K. Chrissafis and D. Bikiaris, "Can nanoparticles really enhance thermal stability of polymers? Part I: an overview on thermal decomposition of addition polymers," Thermochimica Acta, vol. 523, no. 1-2, pp. 1-24, 2011. 

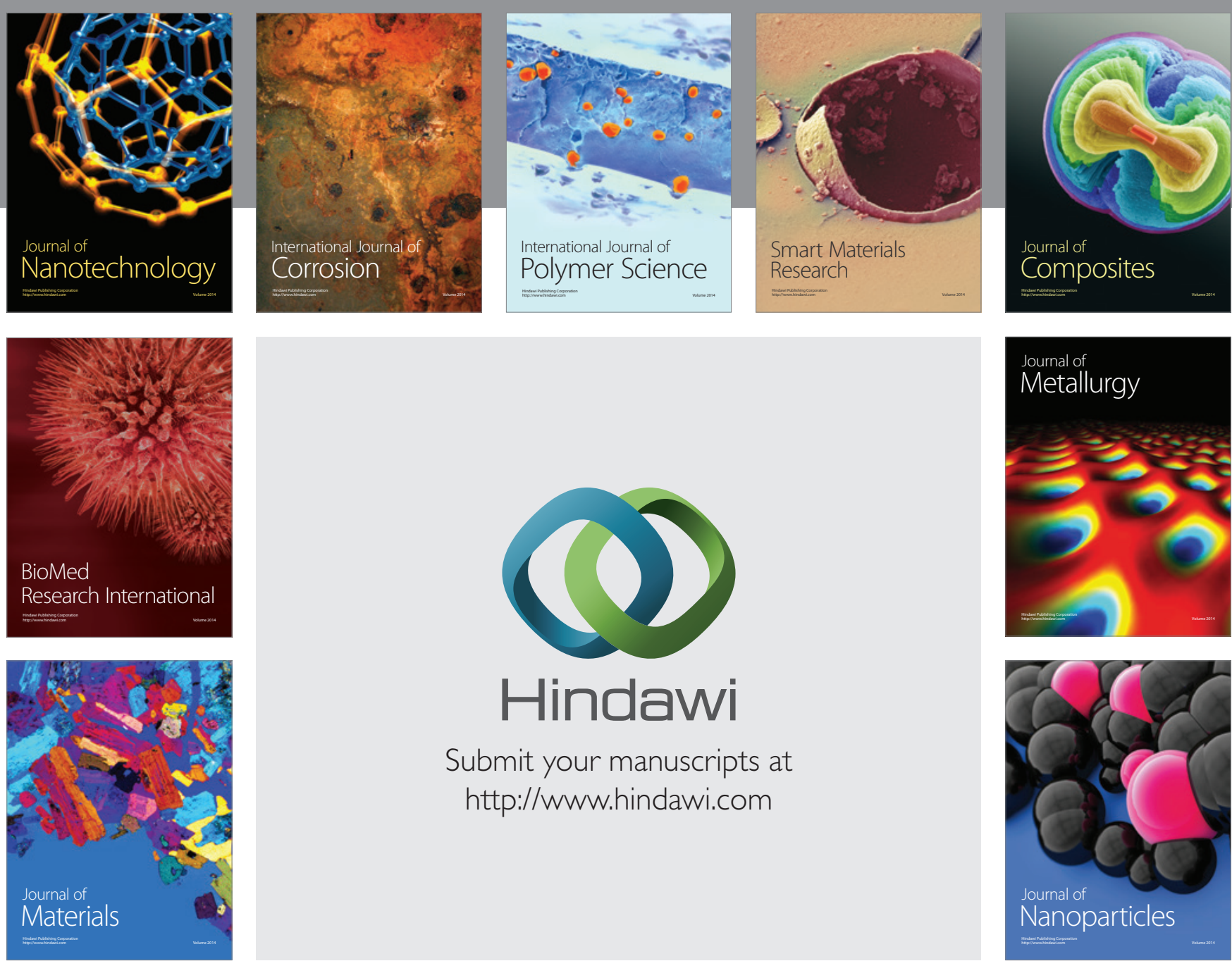

\section{Hindawi}

Submit your manuscripts at

http://www.hindawi.com

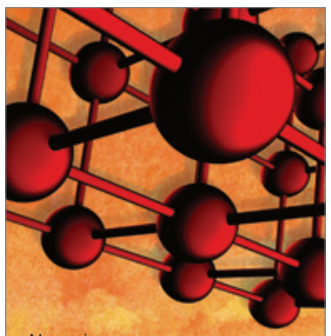

Materials Science and Engineering
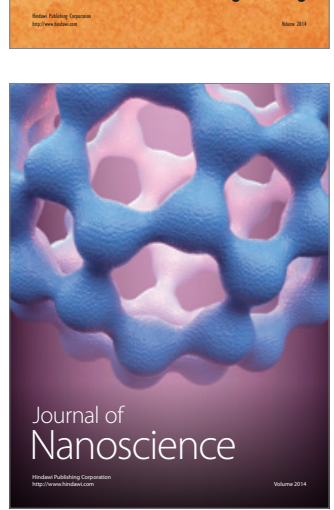
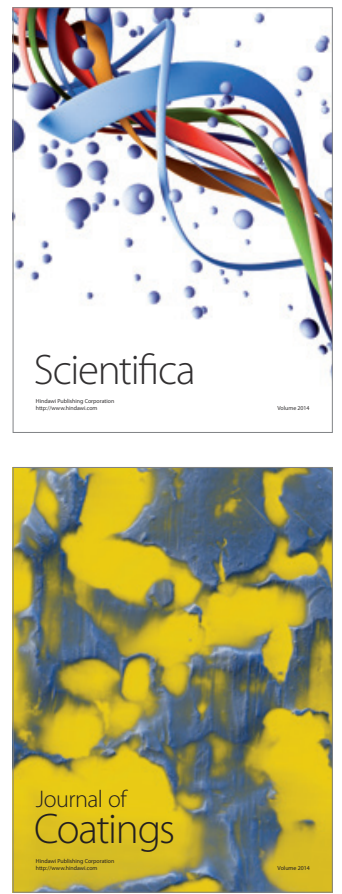
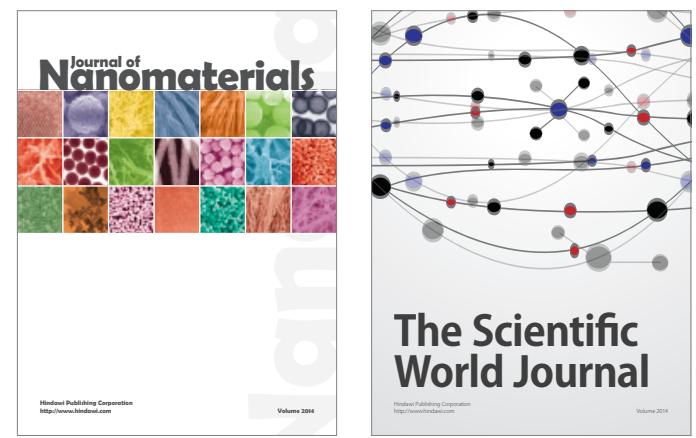

The Scientific World Journal
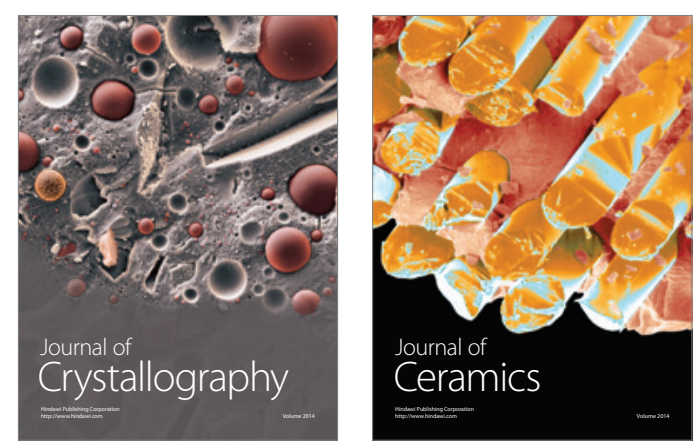
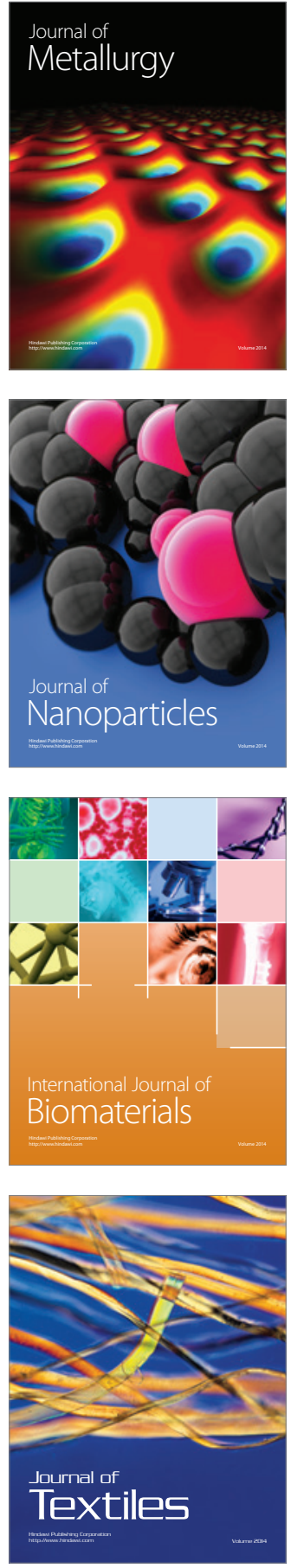